HUMANAS E SOCIAIS

V.8 * N.3 • 2020 • Fluxo Contínuo

ISSN Digital: 2316-3801

ISSN Impresso: 2316-3348

DOI: 10.17564/2316-3801.2019v8n3p386-404
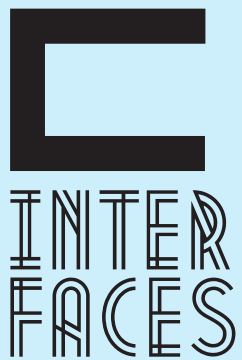

CIENTÍFICAS

\section{A VIOLÊNCIA SIMBÓLICA JUDAICO- CRISTÃ CONTRA A MULHER EM ACÓRDÃO SOBRE A PORNOGRAFIA DE VINGANÇA NO TRIBUNAL DE JUSTIÇA MINEIRO}

CHRISTIAN JEWISH SYMBOLIC VIOLENCE AGAINST WOMEN IN JUDGMENT ABOUT REVENGE PORNOGRAPHY IN MINAS GERAIS COURT

LA VIOLENCIA SIMBÓLICA JUDEOCRISTIANA CONTRA LA MUJER EN SENTENCIA SOBRE LA PORNOGRAFÍA DE VENGANZA EN EL TRIBUNAL DE JUSTICIA DE MINAS GERAIS

Claudete Beise Ulrich ${ }^{1}$

Taiane Martins Oliveira ${ }^{2}$

Vera Gomes Ribeiro Ramos ${ }^{3}$

\section{RESUMO}

0 artigo tem por objetivo desvelar a violência simbólica judaico-cristã contra a mulher que permeia as relações sociais, principalmente, no âmbito do ciberespaço. Do mesmo modo, busca-se averiguar em que medida a ideologia patriarcal que é sustentada pelo discurso religioso cristão permeia os votos dos desembargadores do Tribunal de Justiça de Minas Gerais. Por meio do estudo de precedentes do Tribunal Mineiro sobre a divulgação não consentida de imagem íntima se constatou um modo de funcionamento discursivo religioso em acórdão do Poder Judiciário. Isto é, o acórdão está precipuamente enquadrado na tipologia jurídica, mas o voto analisado trazia marcas do discurso religioso. Nunca é demais lembrar que o voto jurídico deveria ser lastreado pelo manto da laicidade.

\section{PALAVRAS-CHAVE}

Violência Simbólica. Ciberviolência. Pornografia de Vingança. Gênero. Mulher. 


\section{ABSTRACT}

The article aims to reveal Judeo-Christian symbolic violence against women that permeates social relations, especially within the scope of cyberspace. In the same way, the aim is to investigate to which extent the patriarchal ideology that is supported by the Christian religious discourse pervades the votes of the judges of the Court of Minas Gerais. Through the Minas Gerais Court's precedents study about not consented propagation on intimate image, it became clear the religious discourse in judiciary judgments. That is, the judgment is primarily framed in the typology, but the vote under analysis is marked by religious discourse. Never hurts to remember that the legal vote should be backed by the cloak of impartiality.

\section{KEYWORDS}

Symbolic violence. Cyberviolence. Revenge pornography. Genre. Woman.

\section{RESUMEN}

El artigo tiene como objetivo desvelar la violencia simbólica judeocristiana contra la mujer que impregna las relaciones sociales, principalmente, en el ámbito del ciberespacio. Del mismo modo, se busca determinar en qué medida la ideología patriarcal que es sostenida por el discurso religioso cristiano impregna los votos de los magistrados del Tribunal de Justicia de Minas Gerais. A través del estudio de precedentes del Tribunal de Minas Gerais sobre la difusión no consentida de imagen íntima se ha establecido un modo de funcionamiento discursivo religioso en sentencia del poder judicial. Es decir, la sentencia está firmemente enmarcada en la tipología jurídica, pero la votación analizada tenía marcas de un discurso religioso. Nunca es demasiado recordar que la votación jurídica debería ser ponderado a través del manto de la secularidad.

\section{PALABRAS CLAVES}

Violencia simbólica. Ciber violencia. Pornografía de venganza. Género. Mujer. 


\section{INTRODUÇÃO}

A intimidade na atualidade não é tratada da mesma maneira que outrora; a rede mundial de computadores foi responsável pela cisão dos muros entre o público e privado, permitindo a exteriorização contínua e diária de doses de intimidade de cada internauta. Com a propagação das redes sociais (Orkut, Facebook, Instagram) e dos comunicadores de mensagem (Whatsapp e Telegram) passou a ser evidenciado tênue limite entre a intimidade e a exposição. Não sem motivo já se debate na academia brasileira sobre a extimidade virtual, isto é, "a exposição voluntária em ambientes sociais de elementos da intimidade pessoal” (BOLESINA, 2016, p. 166).

Em razão disso, é que o presente trabalho tem por objetivo identificar e evidenciar como o cristianismo que está encrustado na sociedade brasileira contribui para a violência simbólica contra a mulher, principalmente, com vistas nas ciberviolências da contemporaneidade, evidenciando entre outras coisas como o conservador Tribunal de Justiça de Minas Gerais está impregnado por visões machistas e deveras sexistas, as quais são chanceladas pela religião cristã. Para tanto será necessário alinhavar as ideias de Pierre de Bourdieu no que se refere ao conceito de habitus e violência simbólica, bem como noções do conceito junguiano sobre os arquétipos e o inconsciente coletivo.

O método dedutivo irá permear a análise, por meio da pesquisa bibliográfica-documental. Há uma multiplicidade de áreas de conhecimento utilizadas no processo de observação, coleta e processamento das informações, principalmente, a ciência da religião, filosofia, psicologia e o direito, buscando compreender e destacar as estruturas de poder correlatas a violência de gênero e a pornografia de vingança.

É possível perceber por meio do estudo que o Poder Judiciário mineiro está contaminado por discursos de cunho ideológico que sustentam e legitimam a violência simbólica contra a mulher nos casos de pornografia de vingança, podendo ser percebido, inclusive, conteúdos discursivos que se assemelham muito com os discursos de cunho religioso. Assim, é possível observar que a figura do magistrado que deveria se fazer representar como isenta de qualquer tipo de discurso de cunho religioso e, portanto, dotado de laicidade na sua atuação judicante, vez que os votos por ele prolatados são a materialização e a consagração do Estado Democrático de Direito, acabam evidenciando, na verdade, mostras arbitrárias do discurso religioso judaico-cristão.

\section{A VIOLÊNCIA SIMBÓLICA LEGITIMADA PELO CRISTIANISMO POR MEIO DOS MITOS}

É necessário registrar que de acordo com o pensamento junguiano o inconsciente é formado de duas camadas, a camada mais profunda é o que ele chama de inconsciente coletivo, pois, dotada de universalidade, isto é, "são idênticos em todos os seres humanos, constituindo, portanto um substrato psíquico comum de natureza psíquica suprapessoal que existe em cada indivíduo" (JUNG, 2002, p. 15). Portanto, por meio do inconsciente coletivo cada indivíduo herda informações de seus antepassados, trazendo e carregando consigo experiências deles. Assim, é possível intuir que pelo incons- 
ciente coletivo cada indivíduo é portador de um manancial de informações, as quais estão presas na caverna da mente, precisando apenas de que a exploração re(inicie) aquele pensamento. E por qual meio o ser humano consegue acessar a caverna inexplorada? Por meio dos arquétipos que são o seu "conteúdo inconsciente, o qual se modifica através de sua conscientização e percepção, assumindo matizes que variam de acordo com a consciência individual” (JUNG, 2002, p. 17).

É por meio do conteúdo inconsciente, ou seja, dos arquétipos, entre eles, o mito, que é possível perceber a manutenção e a perpetuação da violência simbólica contra a mulher. Romper o ciclo do inconsciente coletivo é difícil, já que para isso é necessário que cada ser humano aumente o nível da sua própria consciência, rompendo com os resquícios encrustados por meio dos arquétipos.

Bourdieu na mesma linha de Jung formula o conceito de habitus, que é a repetição de comportamentos incorporados e internalizados da sociedade por meio de mecanismos do inconsciente. Em suas precisas palavras o habitus "é esse princípio gerador e unificador que retraduz as características intrínsecas e relacionais de uma posição em um estilo de vida unívoco, isto é, em um conjunto unívoco de escolhas de pessoas, de bens, de práticas" (BOURDIEU, 1996, p. 22).

Nesta esteira, para compreender a violência simbólica é necessário assinalar o que é poder simbólico: "poder quase mágico que permite obter o equivalente daquilo que é obtido pela força (física ou econômica), graças ao efeito específico de mobilização, só se exerce se for reconhecido, quer dizer, ignorado como arbitrário" (BOURDIEU, 1989, p. 14). Ou seja, a violência simbólica é fruto desse poder que é exercido sem a força física imediata, decorre da construção social por meio da cumplicidade entre aquele que o exerce e o indivíduo assujeitado.

Portanto, romper com o imaginário tecido e diuturnamente construído por meio do poder e da violência simbólica em detrimento da mulher não é tarefa das mais fácies. Principalmente, ante as representações mitológicas do ser feminino como figura que rompe com a ordem cósmica e atiça os desejos mais sórdidos do homem.

Os mitos são capazes de produzir infinitas construções discursivas sobre determinado tema, ele é capaz de transformar, reescrever e perpetuar projeções da realidade, proporcionando diversas interpretações e reinterpretações, já que "o mito é uma ideia transcendente que escapa a toda tomada de consciência” (BEAUVOIR, 2016, p. 331). Especificamente, no que se referem às mulheres, em regra, os mitos buscam demonstrar a necessidade de elas serem subservientes, recatadas e imaculadas.

0 mito dos Anjos Vigilante da cultura judaica serviu de base para influenciar o pensamento cristão, por meio dele é possível verificar que a mulher mais uma vez foi representada como o elemento provocador do caos. No mito os anjos celestiais responsáveis por vigiar os humanos e manter a ordem, encantam-se pela beleza feminina, principalmente, em razão de seus cabelos, os quais à época pela cultura judaica eram considerados símbolo erótico. E os anjos, infringindo as regras, rompendo com a organização cósmica, resolvem ir a terra para satisfazer seus desejos. Na terra eles enamoram-se com as mulheres e do relacionamento nascem gigantes que desestabilizam a harmonia do local, já que passam a comer toda a comida existente, ocasionando a fome. E os gigantes não satisfeitos e insaciados, acabam também por comer os próprios seres humanos ${ }^{4}$.

4 A narrativa pode ser verificada na integralidade nos trabalhos de Kenner Terrra (De guardiões a demônios. A história do 
Tal mito serviu de influência para o apóstolo Paulo na Igreja Primitiva registrar a necessidade de a mulher usar o véu na cabeça (1Co 11:6-10) como forma de evitar que as mulheres provocassem tentações nos anjos e no ser masculino. Afinal, se as mulheres tiveram o poder de seduzir seres angelicais, dotados de virtudes, subvertendo a ordem, poderia fazê-lo novamente. E, mais, se elas puderam corromper os anjos, o que dirá em relação aos homens, que, são essencialmente imperfeitos e fracos.

Por meio do mito da criação do mundo articulado com o mito da serpente são mostras da simbologia da mulher para a sociedade cristã. No primeiro a mulher é colocada de forma secundária na organização do mundo, já que derivada da costela do homem, o que, por via de consequência, possibilitaria a dependência, a sujeição e a obediência. No segundo, a astúcia do ser feminino que come o fruto proibido e alcança a verdade, o conhecimento, é interpretado, na verdade, como o desarmonizador, subversor e fonte do mal. O olhar mítico judaico-cristão é fonte de "uma etiologia demoníaca em estreita relação com a mulher e sua sexualidade. Seu corpo e sua beleza são as causas da existência dos demônios" (TERRA, 2015, p. 106).

O cristianismo é permeado pelas ideias de Santo Agostinho que respalda seu pensamento nas ideias de platônicas, dando primazia a alma e criando no imaginário a repulsa pelo corpo. Agostinho desenvolve sua filosofia com base na aversão pelo ser feminino, condenando a sua sensualidade e censurando o prazer. A mulher é fundamentalmente portadora do mal para o pensamento dele. 0 corpo, o prazer, são os responsáveis pela perdição do homem, enquanto a mulher é o paradigma da tentação.

A mulher para ele é a portadora dos males da perdição. É o que se verifica em Confissões: "quando Ordenas que me abstenha da concupiscência da carne, da concupiscência dos olhos e da ambição do século" (AGOSTINHO, 2007, p. 105). E, também, em Cidade de Deus “a ira e a voluptuosidade (libido) são as partes viciosas da alma pois se lançam em agitada desordem mesmo para atos que a sabedoria não permite que se realizem" (AGOSTINHO, 1996, p. 1295).

Portanto, não é sem motivo que "numa religião em que a carne é maldita, a mulher se apresenta como a mais temível tentação do demônio” (BEAUVOIR, 2016, p. 134). Isto é, a construção discursiva mítica em face da mulher é continuamente desenvolvida de forma linear na história da humanidade, perpetuando no imaginário da sociedade ocidental o sentimento de repulsa pelo ser feminino e associando-a a figura do mal e do caos. Logo, não há dúvidas quanta às violências simbólicas que são reproduzidas pelos mitos, o que deflagra por meio de tais constatações a necessidade de se buscar desconstruir os paradigmas e aumentar a consciência (aqui utilizado no sentido junguiano), visando compreender o poder simbólico e a violência de gênero ocorridas no ciberespaço.

\subsection{GÊNERO, CIBERCULTURA E A EXTIMIDADE VIRTUAL}

No presente trabalho gênero deve ser interpretado como uma categoria de análise. Isto é, parte-se da premissa de que o gênero é uma “diferença socialmente construída” (BOURDIEU, 2014, p. 24). É neste sen-

imaginário do pneuma akatharton e sua relação com o mito dos vigilantes) e ainda em Anderson Dias de Araújo (Anjos Vigilantes e Mulheres Desveladas: Uma relação possível em 1 Coríntios 11,10?), os dois apresentam importantes considerações sobre a construção discursiva decorrente da mitologia. 
tido que a clássica frase "ninguém nasce mulher: torna-se mulher" foi cunhada (BEAUVOIR, 2016, p. 11). Ora, por meio dela é possível se assimilar que há uma construção social do que é o ser feminino, podendo, inclusive, tal construção propiciar a exteriorização de preconceitos. Afinal, ao se categorizar e edificar características e adjetivos exclusivos de determinada grupo em razão do sexo, acaba-se por produzir estereótipos que por via de consequência poderão produzir preconceito, já que "os estereótipos são, por vezes, exageradamente generalizados, imprecisos e resistentes a novas informações” (MYERS, 2014, p. 248).

Judith Butler vai ao encontro do pensamento de Bourdieu e Beauvoir e registra que o gênero é uma construção social. Porém, Butler é um pouco mais ousada que seus predecessores e assinala que não é só o gênero que é fruto dessa construção social, para ela há uma construção discursiva da heterossexualidade compulsória e seu sistema binário hierárquico. Isto é, para ela até o sexo é construção social. Segundo a autora americana “talvez o próprio construto chamado 'sexo' seja tão culturalmente construído quanto o gênero; a rigor, talvez o sexo sempre tenha sido gênero, de tal forma que a distinção entre sexo e gênero revela-se absolutamente nula” (BUTLER, 2018, p. 27).

Fato é, a construção discursiva da heteronormatividade e o sistema binário de gênero são pressupostos cruciais para evidenciar as relações de privilégio da categoria de análise de gênero. Nesta pesquisa parte-se do sistema binário de gênero com a finalidade de demonstrar as violências simbólicas em faces das mulheres. Obviamente, que seria mais adequado não fazer uso da relação dual - homem e mulher, já que "fazendo uso de gênero dessa forma, agregam-se à reflexão valores e conceitos masculinos, tradicionais e patriarcais, sem provocar verdadeiras mudanças na reflexão teórica e prática” (ULRICH, 2006, p. 39). Porém, os dados colhidos pelo Conselho Nacional de Justiça e a própria jurisprudência do Tribunal de Justiça de Minas Gerais sobre o assunto adotam o sistema do binarismo de gênero, motivo pelo qual prosseguir-se-á na pesquisa de acordo com tais parâmetros.

A mulher do século XXI está sujeita há uma série de violências, dentre elas as relacionadas às agressões sexuais, patrimoniais, físicas (atentados contra a sua vida em razão de ser mulher - feminicídio) e aquelas que ocorrem no âmbito do espaço virtual. A última pesquisa do DataSenado registrou os seguintes números sobre as violências sofridas pelas mulheres entrevistadas: $67 \%$ violência física; $47 \%$ violência psicológica; $36 \%$ violência moral e 15\% violência sexual. Apontaram ainda que os fatores que induziram à agressão foram: o álcool - $24 \%$; brigas e discussões - 19\% e ciúme - 16\% (SENADO FEDERAL, 2017, p. 3; 12).

Dado importante apresentado é que em regra as mulheres que são mães têm mais que o dobro (34\%) de chances de sofrer violência em relação àquelas que não têm filhos (15\%), conforme DataSenado (SENADO FEDERAL, 2017, p. 7). As mulheres ouvidas também consignaram que o Brasil é um país muito machista conforme $69 \%$ das entrevistadas. Também apontaram que consideram adequada a posição do judiciário de processar o autor da agressão mesmo contra a vontade da ofendida, $97 \%$ das entrevistadas (SENADO FEDERAL, 2017, p. 9; 14). Isto significa que a maioria das mulheres entrevistadas prefere abdicar da sua autonomia individual de escolha quanto ao processamento dos crimes cometidos em face delas (o que se chama de ação penal pública condicionada) em nome do coletivo.

Quando perguntadas sobre “o que leva uma mulher a NÃO denunciar a agressão?": 71\% responderam que por medo do agressor; $32 \%$ por preocupação na criação dos filhos; $29 \%$ em razão de dependência eco- 
nômica; $25 \%$ por não acreditarem na efetiva punição; $20 \%$ pela vergonha da agressão; $17 \%$ por acreditarem que seria a última agressão e 15\% por não conhecerem seus direitos (SENADO FEDERAL, 2017, p. 33).

Oportuno mencionar que houve um aumento do número de mulheres que foram vítimas de algum tipo de violência praticado por homens no âmbito das relações doméstica e familiares, o índice passou de 18\%, em 2015, para 29\% por cento, em 2017 (SENADO FEDERAL, 2017, p. 2). O que deve ser interpretado como alerta laranja para o estudo das violências de gênero. Afinal, o que contribuiu para o citado aumento? Ausência de políticas públicas eficientes no que tange ao caráter educativo? Onda político-religiosa conservadora?

Fato é, as mulheres são vítimas contumazes de violências, entre as quais, a cibernética. A violência cibernética contra a mulher, em regra, está relacionada a fatos cometidos em desfavor da moral (injúria, difamação e calúnias), ordem psicológica (ameaça) e a sua intimidade (divulgação não consentida de imagem íntima). Ou seja, a partir do surgimento da internet outras formas de violências se difundiram, mudando os meios e os métodos de execução delas em face da mulher. Porém, a raiz dessas violências é a mesma: sempre ligadas à violência simbólica, vez ou outra, legitimada pelo cristianismo, em razão das hachuras desenhadas no imaginário ocidental de cada indivíduo.

Conforme dados da SaferNet Brasil 70,5\% dos atendimentos relacionados a divulgação não consentida de imagem íntima (pornografia de vingança) foram praticados contra mulheres e $67,4 \%$ dos atendimentos por cyberbullying são de vítimas do gênero feminino (SAFERNET BRASIL, 2017, ON-LINE). O número de mulheres vítimas de violências praticadas no espaço virtual é alarmante. Com base nos referidos dados estatísticos é possível considerar o grau de relevância do estudo.

No ciberespaço se desenvolvem as novas violências de gênero, é no cenário da rede mundial de computadores em suas comunidades virtuais (Facebook e Instagram) e nos seus comunicadores de mensagens (Whatsapp e Telegram) que as relações dos usuários (internautas) produzem a cibercultura. E é no ciberespeaço que se alastra a violência cibernética contra a mulher. Na rede produz-se a cibercultura que é o "conjunto de técnicas (materiais e intelectuais), de práticas, de atitudes, de modos de pensamento e de valores que se desenvolvem juntamente com o crescimento do ciberespaço" (LÉVY, 1999, p. 360).

Isto é, a cibercultura integra a cultura, a cultura que é produzida pelos meios tecnológicos. É nela que se percebe o objeto de análise da presente pesquisa, vez que a divulgação não consentida de imagem íntima é disseminada no ambiente virtual. Nunca é demais lembrar que o aposto de virtual deve ser entendido como físico e nunca como real. Virtual e físico são opostos que se complementam. 0 virtual não deve jamais ser interpretado como irrealidade. Neste sentido, "o que se tem é 'físico e virtual'. Logo, não trata-se da oposição real x virtual, mas sim de uma complementação entre o físico e o virtual” (BOLESINA, 2016, p. 125).

Com tais premissas definidas, o próximo questionamento é: o que leva o fascínio contemporâneo em relação à exposição da intimidade nas redes sociais? Socorre-se a filosofia sartriana, a qual nos mostra que o grande deslumbramento do ser humano é "ser-visto-pelo-outro", já que o olhar do outro remete a si mesmo. Ou seja, expor-se e revelar-se ao outro é também exercício de autoconhecimento. Nas precisas palavras do filósofo “eu me vejo porque alguém me vê” (SARTRE, 2007, p. 335). 
Indo além, pode-se franquear a ideia, inclusive, de que há um grande frisson no ser humano quando também pode "ver-sem-ser-visto". Isto é, a busca constante do internauta de publicar, compartilhar e expor não é sem razão. Ele fala desse encantamento nos seguintes termos "eu gostaria de ser invisível e ficar aqui vendo ele sem ele me ver” (SARTRE, 2019, p. 539). O ciberespaço possibilita o experimento de olhar e não ser visto. É o que diuturnamente fazemos quando acessamos redes sociais, muitas vezes sequer sabemos quem ao certo tem visto nossas publicações.

Obviamente que as grandes empresas sabem da nossa situação existencial e da premente necessidade de migalhas. Por isso, nos possibilitam ganhar "curtidas" e em outras situações nos permitem verificar as pegadas da visualização (o Instagram permite o usuário verificar quem visualizou a postagem colocada na aba "história" e quando se posta vídeo na linha do tempo, por exemplo). Ora, o olhar do outro nos provoca a experiência de "ser-Para-outro na forma de uma posse. [...] O olhar do outro modela meu corpo em sua nudez, causa seu nascer, o esculpe, o produz como é, o vê como jamais o verei. O outro detém um segredo: o segredo do que sou" (SARTRE, 2007, p. 454).

A internet, portanto, apenas permitiu que essa necessidade constante de "ser-visto-pelo-outro" e de "ver-sem-ser-visto" do ser humano fosse potencializada a ponto de romper as barreiras da intimidade. Ocorre na contemporaneidade a dessacralização da intimidade por meio da exposição virtual. Isto é, "as informações postadas na tela alcançam uma visibilidade nunca antes imaginada, afrouxando as fronteiras, desmoronando as paredes e deslocando a intimidade para fora do privado, na 'Ágora' contemporânea que é a internet" (MATTOS, 2015, p. 12).

A exposição virtual da intimidade evidencia o fenômeno da extimidade virtual: "marcante desejo de compartilhar informações, de expor a si mesmo através de fotos, frases, testemunhos, relatos confessionais, bem como essa nova possibilidade de estabelecer contatos fortes no espaço êxtimo da rede" (MATTOS, 2015, p. 80). Segundo Bolesina o direito de extimidade virtual é a conjunção do direito de intimidade com o direito de liberdade de expressão. Para o autor o direito de extimidade é a exteriorização dessa intimidade para o social, mas não para o público. Logo, aquilo que se posta não é público no sentido de estar à disposição de todos, pelo contrário, a expressão da intimidade é para o social, para aquele grupo específico (BOLESINA, 2016, p. 142).

Com tais considerações conceituais e introdutórias, convida-se o leitor ao próximo tópico do artigo sobre a pornografia de vingança, a jurisprudência do Tribunal de Justiça de Minas Gerais, a violência simbólica de gênero e a cumplicidade do cristianismo para a produção de discursos misóginos e sexistas, contribuindo para a ideologia patriarcal e machista.

\section{A COMPOSIÇÃO BINÁRIA DO TJMG E A RELIGIÃO PROFESSADA PELOS MEMBROS}

Em pesquisa recente realizada pelo Conselho Nacional de Justiça verifica-se que houve uma evolução do número de mulheres que ingressaram na carreira da magistratura estadual dos anos 1990 até 2010, respectivamente, 25\% para 40\%, depois de 2011 aconteceu pequeno declínio e o índice passou a ser de $36 \%$ (CNJ, 2018, p. 9). 
Ficou consignado, também, que, atualmente, no Brasil, apenas $25 \%$ das mulheres são desembargadoras, enquanto o percentual de juízas titulares corresponde a $39 \%$ e de juízas substitutas é de 44\% (CNJ, 2018, p.10). Isto é, na média geral, quando do ingresso na carreira à mulher está sujeita a critérios substancialmente objetivos, concurso público de provas e títulos, a igualdade de gênero está próxima de ser consolidada. Por outro lado, quando o cargo depende de indicação em lista, analisando-se critérios de merecimento e antiguidade, o número de mulheres é diminuto. Portanto, as mulheres não conseguiram alcançar ainda a igualdade nos cargos do alto escalão do Poder Judiciário, aqueles de mais prestígio.

Especificamente, no Tribunal de Justiça de Minas Gerais, o percentual de magistradas ativas é de 32\% (CNJ, 2019, p. 25). No Superior Tribunal de Justiça, dos trinta e três cargos de ministro, apenas seis mulheres ocupam vaga no tribunal conhecido como da Cidadania (STJ, 2019, ON-LINE), no Supremo Tribunal Federal não é diferente, apenas duas mulheres para a Corte Constitucional com onze vagas (STF, 2019, ON-LINE). Assim, é de se concluir pelos dados apresentados pela existência de uma hegemonia masculina nos Tribunais brasileiros.

Na pesquisa do Conselho Nacional de Justiça (CNJ) também foi traçado o perfil religioso dos magistrados. Percebe-se que na região sudeste (Minas Gerais, Espírito Santo, São Paulo e Rio de Janeiro) quase $80 \%$ dos magistrados declararam possuir algum tipo de religião, sendo que 55,6\% são católicos; 5,1\% (evangélicos tradicionais; 2,2\% evangélicos neopentecostais; $13,4 \%$ espíritas; portanto, $76,3 \%$ são de religiões ligadas ao cristianismo (CNJ, 2018, p. 21). Isto é, há uma hegemonia cristã.

Não restam dúvidas de que o Poder Judiciário brasileiro é hegemônico: masculino-cristão. Partindo de tal premissa, passa-se a estudar os precedentes do Tribunal mineiro sobre a divulgação não consentida de imagem íntima da mulher, buscando averiguar as consequências de tal hegemonia para a resolução dos conflitos. A exteriorização da decisão em segundo grau acontece por meio do acórdão judicial, que, em regra, é proferido por três desembargadores, por meio deles se fará a análise dos dados pesquisados. No próximo tópico mostrar-se-á a metodologia da pesquisa e os resultados obtidos.

\subsection{OS CASOS DE PORNOGRAFIA DE VINGANÇA DO TJMG: ANÁLISE QUANTITATIVA E QUALITATIVA}

A pesquisa de jurisprudência sobre casos de pornografia de vingança no Tribunal de Justiça de Minas Gerais iniciou por meio de busca de palavras-chaves. Portanto, o método utilizado foi o de tentativa e erro. As palavras (pornografia de vingança, divulgação de fotos íntimas, divulgação de vídeos íntimos, vídeo íntimo, revenge porn) foram lançadas no buscador de jurisprudência do sítio eletrônico do Tribunal mineiro, voltando os seguintes resultados:

\begin{tabular}{|c|c|}
\hline \multicolumn{2}{|c|}{ Tribunal de Justiça de Minas Gerais } \\
\hline Palavras-chave: & Resultados pesquisa: \\
\hline pornografia de vingança & 0 (zero) acórdão \\
\hline divulgação de fotos íntimas & 7 (sete) acórdãos \\
\hline
\end{tabular}




\begin{tabular}{|c|c|}
\hline \multicolumn{2}{|c|}{ Tribunal de Justiça de Minas Gerais } \\
\hline divulgação de vídeos íntimos & 1 (uma) acórdão \\
\hline revenge porn & 0 (zero) acórdão \\
\hline divulgação de vídeo conteúdo pornográfico & 1 (um) acórdão \\
\hline
\end{tabular}

Portanto, o termo "revanche sexual" não retornou resultado, de igual modo o termo revenge porn. As expressões "divulgação de fotos íntimas, divulgação de vídeos íntimos e divulgação de vídeo conteúdo pornográfico", retornaram nove resultados, conforme o quadro acima. Portanto, os seguintes julgados foram analisados: 0009872-16.2012.8.13.0411, 5004880-67.2016.8.13.0707, 500074983.2015.8.13.0707, 1.0223.07.223690-2/001, 1.0476.14.000387-4/001, 1.0016.12.000084-5/002, 1.0481.08.088005-9/001, 1.0134.16.012570-1/001 e 1.0481.08.088005-9/001.

Isto é, todos os acórdãos retornados da busca com os critérios supracitados foram analisadas em uma leitura flutuante. 0 período das decisões é do ano de 2007 ao mês de agosto do de 2019. Para análise dos julgados, primeiro foi observado características dos processos pelo número de ocorrências (quantitativa), em segundo lugar a apreciação qualitativa dos dados, com vistas nos argumentos constantes na fundamentação das decisões.

A análise qualitativa dos julgados será feita por meio de análise de discurso, tentando identificar, por meio dos votos de cada desembargador, se há explicitamente ou implicitamente traços do discurso religioso, com vistas em detectar interdiscursividades, dialogismos e marcas específicas do campo da religião. Portanto, o texto é a unidade observacional, o corpus é o voto acórdão.

O banco de dados do Tribunal de Justiça de Minas Gerais é público e está disponível na rede mundial de computadores. Caso o leitor queira ter acesso à integra dos julgados basta acessar o sítio (www.tjmg. jus.br), clicar na aba jurisprudência e digitar as palavras-chaves. Todas as decisões estão disponíveis em formato Portable Document Format (PDF) e as ementas foram publicadas no Diário Oficial.

Depois de coletada as decisões do banco de dados foi confeccionado um formulário com o objetivo de extrair dados específicos dos julgados a serem analisados. 0 formulário possibilitou colher e organizar informações básicas sobre: o tribunal de origem; tipo de processo, isto é, se cível ou criminal; número do processo e câmara julgadora; data e publicação do julgado; composição do órgão colegiado pelo sistema binário de gênero; comarca de origem e nome do relator; fundamentos da decisão; decisão tomada por maioria ou unanimidade; valor arbitrado de indenização por dano moral nos processos cíveis e, por fim, os critérios de fundamentação dos votos, se estritamente jurídico ou não.

Antes de iniciar a análise é necessário dizer que nenhum discurso é absolutamente neutro. Assim, não há como afirmar que algo seja puramente jurídico ou propriamente religioso. Porém, há elementos do discurso que são passíveis de se apontar como pertencentes a determinado campo, seja jurídico, seja religioso. Buscar-se-á destacar os traços dos discursos "não-jurídicos" contidos nas decisões do Tribunal de Justiça de Minas Gerais, que, portanto, se assemelham ao discurso religioso de cunho cristão.

O formulário serviu para organizar as decisões proferidas em categorias argumentativas, buscando classificar os fundamentos decisórios em “jurídico" e “não-jurídico”. Obviamente a categorização é 
apenas instrumental, tendo por objetivo verificar o percurso discursivo percorrido pelos desembargadores na elaboração de seus votos. Com isso será possível identificar se os argumentos apresentados nos acórdãos apresentam traços do discurso religioso (implícito ou não) são propriamente jurídicos.

As decisões judicias são sempre constituídas de um texto escrito, o qual exige formalidades específicas. No caso dos acórdãos é imprescindível que sejam compostos de três requisitos básicos: relatório, fundamentação e dispositivo. É na fundamentação que o julgador manifesta as suas ideologias, sendo, portanto, o ponto de partida da análise qualitativa.

É necessário adiantar ao leitor que dos 9 julgados analisados apenas 5 são pertinentes a pesquisa, já que no julgado $n^{\circ} 0009872-16.2012 .8 .13 .0411$ se travou discussão sobre a obrigação do Google Brasil Internet LTDA. em indenizar a requerente pela manutenção de conteúdo de nudez em seus provedores, não houve, portanto, debate sobre a voluntariedade ou não da produção das imagens, tampouco sobre a pessoa responsável pela divulgação. 0 julgado se limitou a questão procedimental no que tange ao Marco Civil da Internet e a responsabilidade do Google pela manutenção do conteúdo em seus provedores.

O segundo julgado descartado é o de número 5000749-83.2015.8.13.0707, pois retrata a condenação de veículo de televisão por vinculação da imagem da autora, sem sua autorização, em matéria jornalística, devido à tentativa de homicídio praticada pelo ex-cônjuge. Portanto, trata-se de julgado de uso indevido de imagem em matéria jornalística e não de divulgação não consentida de imagem íntima. 0 que é de se registrar é que tal acórdão condenou por dano moral a empresa de televisão em $\mathrm{R} \$$ 50.000,00 (cinquenta mil reais). Enquanto a média dos julgados de divulgação não consentida de imagem íntima têm valores inferiores ao ora arbitrado, isto nos faz refletir, inclusive, sobre a valoração do dano moral fixado em julgados de pornografia de vingança e outros referentes ao direito de imagem. Porém, agora, tal perspectiva não ser o objeto de análise.

Os acórdãos criminais foram julgados e publicados antes da vigência das leis 13.718/18 e 13.772/18, que, respectivamente, criminalizaram a divulgação de cena de sexo ou de pornografia e o registro não autorizado da intimidade sexual. Portanto, entende despiciendo a verificação de tais decisões de segunda instância para o presente estudo, já que há regulamentação normativa mais específica e atual para os casos de divulgação não consentida de imagem íntima, por isso, não havendo mais que se falar em crime de extorsão. Assim, deixa de apreciar detalhadamente os seguintes julgados: 2236902-63.2007.8.13.0223 e 0125701-61.2016.8.13.0134.

A primeira constatação é de que todos os julgados analisados nesta pesquisa, por unanimidade, com vista no sistema binário de gênero, foram prolatados apenas por homens, o que reforça os dados anteriormente apresentados pelo Conselho Nacional de Justiça sobre a hegemonia masculina na segunda instância. Os acórdãos analisados não tiveram sequer um voto de relatoria de qualquer desembargadora do Tribunal de Justiça de Minas Gerais.

O quantum fixado em razão da condenação por danos morais não é homogêneo, variando de 10.000,00 (dez mil reais) até 50.000,00 (cinquenta mil reais). Isto é, não há uma quantia pré-definida para reparação do dano moral da mulher vítima da divulgação não consentida de imagem íntima. A média dos valores fixados pelo Tribunal de Justiça de Minas Gerias é irrisória perto da grave violação da imagem e o consequente 
dano moral sofrido pela mulher. Como informado alhures em uma condenação de simples uso de imagem da mulher em programa jornalístico o valor fixado foi mais que o dobro. Muito embora, os valores fixados a título de danos morais sirvam de referência na averiguação da importância dada pelo Poder Judiciário para a violação da intimidade da mulher, o presente trabalho não serve a tal objetivo.

O corpus dos julgados possui certo grau de simetria no que tange há alguns fundamentos jurídico-teóricos. Todos os fundamentos dos julgados introduzem um breve histórico dos fatos e os votos tendem já de início a apontar o autor das divulgações das imagens íntimas (fotografias e vídeos). 0 nexo de causalidade entre o dano e o suposto autor do fato é sempre uma constante dos julgados analisados. No que tange aos fundamentos normativos da decisão os artigos mais repetidos são: 187 e 927, ambos do Código Civil de 2002 e 5ª inciso X, da Constituição Federal.

Os artigos 186 e 927 do Código Civil são recorrentes, pois trazem os requisitos da responsabilidade civil. Portanto, neles estão os elementos caracterizadores da responsabilidade civil: o ato ilícito, a ação ou omissão, voluntária ou involuntária, negligente ou imprudente, causar dano (ainda que moral), demonstração de culpa do agente e a consequente obrigação de reparação. Enquanto o inciso X, do artigo $5^{\circ}$, do texto Constitucional, elenca a expressa obrigação de reparação da violação da intimidade, vida privada, honra e imagem. Portanto, tais artigos servem como referenciais para a boa aplicação do direito e são reveladores do que nesta pesquisa chama-se de voto estritamente jurídico. 0 voto que tem tais marcas discursivas se aproxima do voto fundamentado juridicamente de maneira adequada.

Neste contexto foi possível observar outras capitulações legais que também demonstram a existência de um voto essencialmente jurídico. Por exemplo, aquele voto em que se cita o artigo $1^{\circ}$, da Declaração Universal dos Direitos Humanos, que trata sobre a liberdade e a igualdade de direitos e dignidade. E, ainda, o artigo 11 e 20, do Código Civil, que trata dos direitos de personalidade do indivíduo, entre os quais a imagem, a honra e a intimidade. Obviamente, que não é apenas a mera citação dos referidos artigos que tornam o voto jurídico ou não-jurídico, mas sim, a observância dos requisitos daqueles na decisão e, principalmente, a subsunção do caso concreto a cada um dos critérios especificados na norma.

Fato é, destes critérios apresentados, quando da busca no acervo de jurisprudência do Tribunal de Justiça mineiro, só se verificou um voto que destoa do discurso jurídico, é o voto do desembargador Batista de Abreu da apelação cível n 1.0481.08.088005-9/001, que será analisado no próximo tópico.

\subsection{VOTO “NÃO-JURÍDICO” E AS PROXIMIDADES COM O DISCURSO RELIGIOSO}

É oportuno mencionar que "todo dizer é ideologicamente marcado. É na língua que a ideologia se materializa. Nas palavras dos sujeitos” (ORLANDI, 2005, p. 18). Portanto, todo e qualquer discurso carrega marcas ideológicas. Assim, "um discurso aponta para outros que o sustentam” e ele é dotado de relação de força, isto é, "o lugar a partir do qual fala o sujeito é constitutivo do que ele diz" (ORLANDI, 2005, p. 39). Ou seja, o processo de significação do discurso está imerso nas condições de sua produção. A análise do discurso serve para explicar a produção dos sentidos do discurso.

É de se destacar que “a interpretação é constitutiva da própria língua” (ORLANDI, 2005, p. 78). Não há como desvincular a interpretação da capacidade discursiva, tanto é verdade que determinado discurso pode ser ouvido por duas pessoas diferentes e produzir efeitos distintos. Ora, o então 
deputado Jair Bolsonaro quando se dirigiu para Maria do Rosário também deputada dizendo que não a estupraria, porque ela não mereceria, produziu um discurso com duas possibilidades interpretativas. Primeiro a de que ser supostamente estuprada seria um prêmio, o qual Bolsonaro jamais concederia a Maria do Rosário, reduzindo a mulher em mero objeto, menosprezando a sua condição de ser mulher, a sua própria dignidade. E, ainda, por meio de outra construção discursiva há vozes que reverberam que ele tenha dito que não estupraria a deputada.

Ou seja, é o percurso do discurso e seu modo de funcionamento que caracteriza a interpretação discursiva. 0 discurso não pode ser lido individualmente, ele é fruto de uma teia interdiscursiva, o discurso dialoga com outros discursos. Assim, "o interdiscurso significa justamente a relação do discurso com uma multiplicidade de discursos” (ORLANDI, 2005, p. 80).

Portanto, quando a ministra Nancy Andrighi do Superior Tribunal de Justiça expressa em sua decisão que a fala de Jair Bolsonaro ratifica "a nefasta consequência de reforçar a concepção bárbara de que, nos crimes sexuais, a vítima concorre para a ocorrência do delito”(STJ, 2017, ON-LINE), ela está materializando textualmente o percurso percorrido por meio de seu discurso, demonstrando por qual motivo entende que o deputado atribuiu o atroz crime de estupro como presente, recompensa, quando proferiu os dizeres contra a deputada Maria do Rosário.

Desse modo, para compreender e analisar o discurso é sempre necessário se dispor a verificar a teia dialógica discursiva e buscar perceber "o efeito metafórico, o deslize - o próprio da ordem do simbólico - é lugar da interpretação, da ideologia, da historicidade” (ORLANDI, 2005, p. 80). É sempre bom lembrar que "o dizer (presentificado) se sustenta na memória (ausência) discursiva" (ORLANDI, 2005, p. 81). Isto é, o silêncio também fala. 0 objeto discursivo será buscado nos trechos selecionados do voto do desembargador Batista de Abreu da apelação cível n 1.0481.08.088005-9/001.

O julgado supracitado foi proferido no ano de 2010, isto é, já no século XXI. 0 caso do acórdão tratava de pedidos de indenização por danos morais formulados pela vítima e seus genitores em razão da divulgação não consentida de imagem íntima pelo ex-namorado. A vítima à época dos fatos era menor de idade. A vítima teve sua imagem exposta perante a diminuta comarca de Patrocínio-MG, vez que a gravação da relação sexual realizada pelo então namorado, foi publicada na internet.

Inicialmente, ao que parece, o ex-namorado mostrou o vídeo aos colegas da escola em que a menor estudava e, posteriormente, também, o compartilhou no ciberespaço. Com isso, a menor passou a ser vítima de chacotas e zombarias, culminando, inclusive, ao final, na troca de colégio da menor, com a finalidade de evitar outras humilhações. Ressalta-se, também, que, pela repercussão do caso na cidade, ela teve dificuldades em encontrar outros estabelecimentos de ensino que a aceitassem como aluna. Oportuno registrar ainda que a menor teve que realizar tratamento psicológico, pois, foi achincalhada pela população.

A primeira marca narrativa do julgado que evidencia discurso "não-jurídico" é a seguinte: "tem-se notícia que fez até pose erótica para a câmera. Sabia o que estava fazendo como também sabia o que estava fazendo o seu namorado. Quem enfia o braço em uma jaula com fera sabe do risco de ser ofendida e mutilada" (TJMG, 2010, p. 16). Deve-se observar o discurso que ficou de fora, ou seja, aquilo que o desembargador conscientemente (ou não!) omitiu para chancelar seu posicionamento. 
De pronto, é possível perceber que ele afastou a responsabilidade do homem ao compará-lo com uma fera. Ora, quando o julgador eleva a figura masculina à representação animalesca da fera está afastando a sua humanidade. E ao colocar o homem como animal está dizendo que ele é controlado e guiado basicamente por seus institutos, logo, irracional.

O segundo ponto é descobrir o significado dessa ausência discursiva, pelo texto apresentado, é o de atribuir a responsabilidade pelo vazamento do vídeo íntimo a mulher. Ora, para o prolator da decisão a culpa pelo vazamento das imagens íntimas não é do namorado (o homem quem filmou o ato sexual, mostrou aos amigos e disponibilizou na internet), mas sim, da mulher que deixou filmar a sua intimidade em poses sensuais, a qual teve a audácia de se exibir em posições eróticas para câmera.

A formação discursiva apresentada se aproxima do sexismo, já que privilegia o gênero masculino no que tange a liberdade sexual em detrimento do gênero feminino. Por fim, a formação ideológica que sustenta tal discurso é da sociedade patriarcal, pois, o patriarcado "representa a estrutura que organiza a sociedade, favorecendo uns e obrigando outros a se submeterem ao grande favorecido que ele é, sob pena de violência e morte" (TIBURI, 2018, p. 59)

A segunda marca narrativa pode ser percebida do seguinte excerto:

Concorreu a menor eficazmente para que suas fotos ou filme fossem divulgados. Foi algoz do martírio dos pais. Aliás, não são mártires coisa alguma porque a filha é fruto da educação que lhe foi dada. E foi a própria filha quem os envergonhou. Deveriam cobrar dela a indenização pelo vexame. (TJMG, 2010, p. 16).

O objeto discursivo do trecho é expresso pela dupla vitimização da mulher em decorrência da exposição de seu corpo e de sua sexualidade. Primeiro a mulher é vítima do próprio namorado que divulga e compartilha na internet a sua imagem em estado de nudez, sem o seu consentimento, depois padece de novo sofrimento causado pelo julgador, ao fomentar a culpabilização da mulher pelo vazamento das imagens íntimas. 0 desembargador chega ao disparate de apontar a mulher como algoz da vergonha enfrentada pelos seus pais, evidenciando, de forma clara, o processo de culpa do ser feminino pela exposição de seu corpo.

Na ótica da decisão não é o homem quem divulgou a imagem da mulher nua o malfeitor, mas sim, ela, a mulher, pois permitiu que as fotos fossem feitas e divulgadas. A formação discursiva se aproxima muito da misoginia, já que constrói "uma imagem visual e verbal das mulheres como seres pertencentes ao campo negativo” (TIBURI, 2018, p. 39). A formação ideológica que sustenta tal discurso é do machismo, que, "é um sistema de crenças em que se aceita a superioridade dos homens devido à sua masculinidade” (TIBURI, 2018, p. 63). 0 machismo está contido dentro do patriarcado, faz parte dele e exterioriza seus preconceitos.

Por fim, o desembargador assinala que:

Todo e qualquer sofrimento da moça é consequência de seu ato e traduzido em vergonha, em arrependimento. Queiram ou não a sociedade é machista. A mulher é caça e o homem é caçador. Mudar tal conceito, invertendo-o, piora a imagem da mulher. (TJMG, 2010, p. 16). 
Além de considerar a mulher como algoz do martírio de seus pais, o julgador ainda aponta a figura feminina como portadora da vergonha por seus próprios atos (e não do seu namorado, autor da divulgação das imagens). E neste texto, mais uma vez, o julgador animaliza as relações humanas entre o homem e a mulher. Quando ele diz que a mulher é "caça e o homem é caçador" evidencia-se no imaginário simbólico rasuras de que a mulher pode ser perseguida, acuada e atormentada pela figura do caçador (homem). Ora, isso vai ao encontro da ideia da masculinidade vigorosa, ativa e potente, reforçando a violência simbólica contra a mulher, a formação discursiva sexista e misógina e a ideologia machista-patriarcal.

Mas, afinal de contas, se o discurso não é jurídico, a qual categoria de discurso se assemelha os trechos anteriores? Qual é o discurso fundamental do texto recortado e trazido a baila? Para responder tal questão, primeiro é de se considerar que o discurso jurídico, tal qual o discurso religioso é essencialmente autoritário. Isto é, “a restrição da relação dialógica entre locutor e interlocutor é muito acentuada, senão completa, o que proporciona a instauração de condições para o exercício da dominação sobre o outro" (TORRESAN, 2007, p. 96).

Enquanto em relação ao discurso jurídico estatal do poder judiciário o porta-voz (magistrado) fala em nome do Estado, o porta-voz do discurso religioso fala em nome de Deus. Sempre válida a lição de Bourdieu (2014, p. 39) de que o "Estado é uma entidade teológica, isto é, uma entidade que existe pela crença”. Certo é, que, para falar em nome do Estado (mesmo que se trate de uma ficção jurídica) o magistrado em uma sociedade democrática de direito deve proferir suas decisões com fundamento na Constituição Federal e seus princípios basilares, também nas leis.

Isto é, muito embora o texto analisado retrate trechos de um acórdão eminentemente jurídico, o discurso ora analisado apresenta formações discursivas e ideológicas que vão além do discurso jurídico. A formação ideológica patriarcal e machista se manifesta e materializa em diversas formas, entre as quais, a religiosa e estatal. Da análise entende-se que o Estado por meio do Poder Judiciário se apropriou do discurso religioso para emitir e propagar a ideologia patriarcal na sociedade brasileira. Não há uma textualização explícita sobre o pecado inicial, do mito da concepção virginal de Maria, ou qualquer menção do mito dos Anjos Vigilantes da cultura judaico-cristã, mas, tais referências estão contidas silenciosamente em cada trecho apresentado.

E "o que é silenciado constitui igualmente o sentido do que é dito. As palavras acompanham de silêncio e são elas mesmas atravessadas de silêncio" (ORLANDI, 2005, p. 84-85). A violência simbólica religiosa está encrustada no texto do magistrado, fazendo dele um discurso muito mais religioso a jurídico, em que pese escrito em acórdão do Tribunal de Justiça de Minas Gerais.

\section{CONCLUSÃO}

O corpo para Focault (2017, p. 65) é “a superfície de inscrição dos acontecimentos (enquanto a linguagem os marca e as ideias os dissolvel)". O corpo da mulher nas marcas da linguagem é relacionado ao perigo, a perdição e a tentação. A mulher é colocada nos mitos que permeiam o 
pensamento jaudaico-cristão como desestabilizadora da ordem e fonte da tentação do homem. Os arquéticos coletivos propagam a necessidade da mulher recatada, pura e frágil. Não é sem razão que tal visão ideológica ainda permeie a sociedade e que ela se materialize em voto proferido pelo Tribunal de Justiça de Minas Gerais.

A aversão discursiva em relação a mulher está ligada ao seu corpo. A nudez da mulher espanta e horririfica o homem, tanto é verdade que o desembargador culpa a mulher por ser a portadora da vergonha. Isto é, a mulher recorre ao Poder Judiciário para ter reparado o seu sofrimento, angústia e desespero, pelo compartilhamento de sua imagem, intimidade, extimidade, no ciberespaço, mas, acaba novamente sendo vilipendiada, é revitimizada. A repulsa do feminino e de seu corpo está ligada ao que representa a mulher nos mitos da cultura judaico-cristã.

\section{REFERÊNCIAS}

AGOSTINHO, Santo. A cidade de Deus. Volume II. Lisboa: Serviço de Educação Fundação Calousteg Ulbenkian, 1996. Disponível em: http://charlezine.com.br/wp-content/uploads/A-Cidade-de-Deus2-Agostinho.pdf. Acesso em: 30 dez. 2018.

AGOSTINHO, Santo. Confissões. Tradução Lucia Maria Csernik. 2007. Disponível em: https://img. cancaonova.com/noticias/pdf/277537_SantoAgostinho-Confissoes.pdf. Acesso em: 30 dez. 2018.

\section{BOLESINA, luri. 0 direito à extimidade e a sua tutela por uma autoridade local de proteção de}

dados pessoais: as inter-relações entre identidade, ciberespaço, privacidade e proteção de dados pessoais em face das intersecções jurídicas entre o público e o privado. 2019. Tese (Doutorado em Demandas Sociais e Políticas Públicas) - Universidade de Santa Cruz do Sul, Santa Cruz do Sul, 2016. Disponível em: https://www.unisc.br/images/cursos/stricto/ppgd/teses/2016/luri-Bolesina--Tese.pdf. Acesso em: 10 abr. 2019

BEAUVOIR, Simone de. 0 segundo sexo: a experiência vivida. V. 1; 2. Rio de Janeiro: Nova Fronteira, 2016.

BOURDIEU, Pierre. O poder simbólico. Rio de Janeiro: Editora Bertrand Brasil, 1989.

BOURDIEU, Pierre. Razões práticas: sobre a teoria da ação. Campinas: Papirus, 1996.

BOURDIEU, Pierre. A dominação masculina. Rio de Janeiro: BestBolso, 2014.

BOURDIEU, Pierre. Sobre o Estado: Cursos no Collège de France (1989-92). Tradução R. F. D’Aguiar. São Paulo: Companhia das Letras, 2014. 
BUTLER, Judith P. Problemas de gênero: feminismo e subversão da identidade. Rio de Janeiro: Civilização Brasileira, 2018.

CNJ - Conselho Nacional de Justiça. Perfil sociodemográfico dos magistrados brasileiros. 2018. Disponível em: http://www.cnj.jus.br/files/conteudo/arquivo/2018/09/49b47a6cf9185359256c227 66d5076eb.pdf. Acesso em: 20 ago. 2019.

CNJ - Conselho Nacional de Justiça. Diagnóstico da participação feminina no poder judiciário. 2019. Disponível em: http://www.cnj.jus.br/files/conteudo/arquivo/2019/05/cae277dd017bb4d445 $7755 f e b f 5 e e d 9 f . p d f$. Acesso em: 20 ago. 2019.

FOCAULT, Michel. Microfísica do poder. Rio de Janeiro: Paz e Terra, 2017.

LÉVY, Pierre. Cibercultura. Edição do Kindle. São Paulo: Editora 34, 1999.

JUNG, Carl Gustav. Os arquétipos e o inconsciente coletivo. Petrópolis: Editora Vozes, 2002.

MATTOS, Carolina Mendes Campos Oliveira. Extimidade virtual na conjugalidade: um estudo sartriano sobre a nova perspectiva da intimidade. 2015. Tese (Doutorado em Psicologia Clínica) Pontifícia Universidade Católica do Rio de Janeiro, Rio de Janeiro, 2015.

MYERS, David G. Psicologia social. 10. ed. Porto Alegre: AMGH, 2014.

ORLANDI, Eni Puccinelli. Análise do discurso: princípios e procedimentos. Campinas: Pontes, 2005.

SAFERNET BRASIL. Indicadores Helpline: atendimentos sobre violações de direitos humanos na internet. Disponível em: https://helpline.org.br/indicadores/. Acesso em: 7 ago. 2019.

SARTRE, Jean-Paul. 0 ser e o nada - Ensaio de ontologia fenomenológica. 15. ed. Tradução de Paulo Perdigão. Petrópolis, Rio de Janeiro: Vozes, 2007.

SARTRE, Jean-Paul. O Quarto. 0 muro coletânea de contos de Sartre. Livro 2. Edição Kindle. Recife: Editora Libertas, 2019.

SF - Senado Federal. Violência doméstica e familiar contra a mulher. Brasília: DataSenado, 2017. Disponível em: https://www12.senado.leg.br/institucional/datasenado/arquivos/aumenta-numerode-mulheres-que-declaram-ter-sofrido-violencia. Acesso em: 7 ago. 2019.

STF - Supremo Tribunal Federal. Composição atual. Disponível em: http://portal.stf.jus.br/textos/ verTexto.asp?servico=sobreStfComposicaoComposicaoPlenariaApresentacao. Acesso em: 15 ago. 2019. 
STJ - Superior Tribunal de Justiça. Composição - 28/5/2019. Disponível em: http://www.stj.jus.br/ static_files/STJ/Midias/imagens/COMPOSICAO_MINISTROS.pdf. Acesso em: 15 ago. 2019.

STJ - Superior Tribunal de Justiça. Recurso Especial no 1.642.310 - DF (2016/0264000-5). Disponível em: http://www.stj.jus.br/static_files/STJ/Midias/arquivos/Noticias/REsp\%201642310. pdf.Acesso em: 20 ago. 2019.

TERRA, Kenner Roger Cazotto. Misoginia cósmica na literatura judaico-cristã. Revista Jesus Histórico, Rio de Janeiro: Universidade Federal do Rio de Janeiro, 2015. RJHR VIII: 15. Disponível em: http://www.revistajesushistorico.ifcs.ufrj.br/arquivos15/6-kenner.pdf. Acesso em: 21 fev. 2019.

TIBURI, Marcia. Feminismo em comum: para todas, todes e todos. Rio de Janeiro: Rosa dos tempos, 2018.

TORRESAN, Jorge Luís. A manipulação no discurso religioso. Dialogia, São Paulo, v. 6, p. 95-105, 2007.

TJMG - Tribunal de Justiça de Minas Gerais. Apelação cível n 1.0481.08.088005-9/001. Disponível em: https://www5.tjmg.jus.br/jurisprudencia/pesquisaPalavrasEspelhoAcordao.do?\&numeroRe gistro=1\&totalLinhas=1\&paginaNumero=1\&linhasPorPagina=1\&palavras=|MAGEM\%20DE\%20 MENOR.\%20DIVULGA\%C7\%C30\%20DE\%20V\%CDDEO\%20COM\%20CONTE\%DADO\%20PORNOG R\%C1FICO\&pesquisarPor=ementa\&pesquisaTesauro=true\&orderByData=1\&pesquisaPalavras=Pesq uisar\&. Acesso em: 20 ago. 2019.

ULRICH, Claudete Beise. Recuperando espaços de emancipação na história de vida de ex-alunas de escola comunitária luterana. 2006. Tese (Doutorado em Teologia) - Escola Superior de Teologia São Leopoldo, Instituto Ecumênico de pós-graduação em Teologia, São Leopoldo, Rio Grande do Sul, 2006. 
1 Faculdade Unida de Vitória/ES. Doutorado em Teologia, área de concentração religião e educação pelo Instituto Ecumênico de Pós Graduação da Escola Superior de Teologia. E-mail: claudete@fuv.edu.br

2 Mestrado Profissional em Ciências das Religiões pela Faculdade Unida de Vitória E-mail: taianemartins@hotmail.com

3 Mestranda em Ciências da Religião pela Faculdade Unida de Vitória. E-mail: veragomes.ramos@gmail.com

\section{(2) (1) ( $)$}

Este artigo é licenciado na modalidade acesso abertosob a Atribuição-Compartilhalgual CC BY-SA

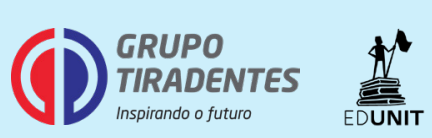

